\title{
Behavioral Disorders Associated with GnRH Agonist Therapy
}

Authors

Affiliation

\section{K. O. Akintola, A. O. Omoruyi, M. B. Foster, S. E. Kingery, K. A. Wintergerst}

Department of Pediatrics, Division of Endocrinology, University of Louisville Kentucky, USA
Key words

gonadotropin

gonadotropin releasing hormone agonists (GnRHa)

- precocious puberty (PP)

central precocious puberty (CPP)

kisspeptin
- hypothalamic-pituitarygonadal (HPG) axis

\section{Abstract \\ $\nabla$}

A number of adverse effects have been described with the use of gonadotropin releasing hormone agonist (GnRHa) therapy in children namely, localized reaction at the site of injection such as pain, erythema, rash, infection or abscess formation and systemic effects such as headache, syncope, fever, or weight gain. These effects have been reported in fewer than $2 \%$ of patients receiving GnRHa.

\section{Case 1 \\ $\nabla$}

received $\quad 30.12 .2013$

first decision 30.12.2013

accepted $\quad 04.02 .2014$

Bibliography

DOI http://dx.doi.org/

10.1055/s-0034-1370943

Published online:

April 25, 2014

Exp Clin Endocrinol Diabetes

Rep 2014; 1: e1-e3

(C) J. A. Barth Verlag in

Georg Thieme Verlag KG

Stuttgart · New York

ISSN 2196-7407

\section{Correspondence}

Dr. K. O. Akintola

Pediatric Endocrinology

University of Louisville

Kentucky

210 East Gray street

Louisville, Suite 803

United States 40202

Tel.: +1/502/6298 821

Fax: $+1 / 502 / 6298824$

chemisola@gmail.com

License terms
A 3-year-old female with a history of central precocious puberty (CPP) was brought to the clinic by her parents requesting immediate removal of the histrelin subcutaneous implant that was placed 3 days earlier because she had become extremely aggressive and emotionally labile. 6 months prior, the patient was diagnosed with CPP and treatment was initiated with $7.5 \mathrm{mg}$ of intramuscular leuprolide given every 28 days. Subsequently, she was noted to have mood and behavior changes that included waxing and waning of aggression. Her parents also correlated these behaviors to within a few days before and after the leuprolide injections. In an attempt to mitigate these "mood swings", a histrelin subcutaneous implant was prescribed.

Approximately $72 \mathrm{~h}$ after successful placement of the histrelin implant, she had an acute exacerbation of her aggressive behavior. In contrast to her normal behavior, she would kick, scream, cry uncontrollably and even bite other children without inciting events. Non-pharmacologic behavior modification therapies were attempted unsuccessfully for 6 months, and the histrelin implant was subsequently removed. Upon removal, the patient had immediate and complete resolution of behavioral symptoms.
While psychological changes have been reported in adult women receiving therapy, these types of adverse events have not been well documented in children. In this report, we describe 3 distinct cases of acute behavioral problems including emotional lability and aggression that were observed in patients being treated with GnRHa implant for central precocious puberty and with dramatic improvement of psychologic changes upon the discontinuation of therapy.

\section{Case 2}

$\nabla$

A 4-year-old female who presented to her physician with advancing secondary sexual characteristics was diagnosed with CPP after an endocrinology evaluation and GnRH stimulation testing. Before therapy began, the patient was known to have some mild behavioral issues requiring only behavioral intervention. Upon placement of the histrelin implant, her behavior dramatically worsened. She became uncontrollable and very aggressive, including biting and kicking others, and was noted to plant feces on furniture surfaces in her home. Within one month of the histrelin implantation, she was subsequently admitted for inpatient psychiatric Intervention. However, her agitation remained difficult to manage until the implant was eventually removed. Within 1 week of removal, there was a noticeable decrease in agitation followed by a general improvement in her behavior.

\section{Case 3 \\ $\nabla$}

A 7-year-old autistic female diagnosed with CPP underwent subcutaneous placement of histrelin. Although normally calm and friendly, she became aggressive and violent, especially towards her 


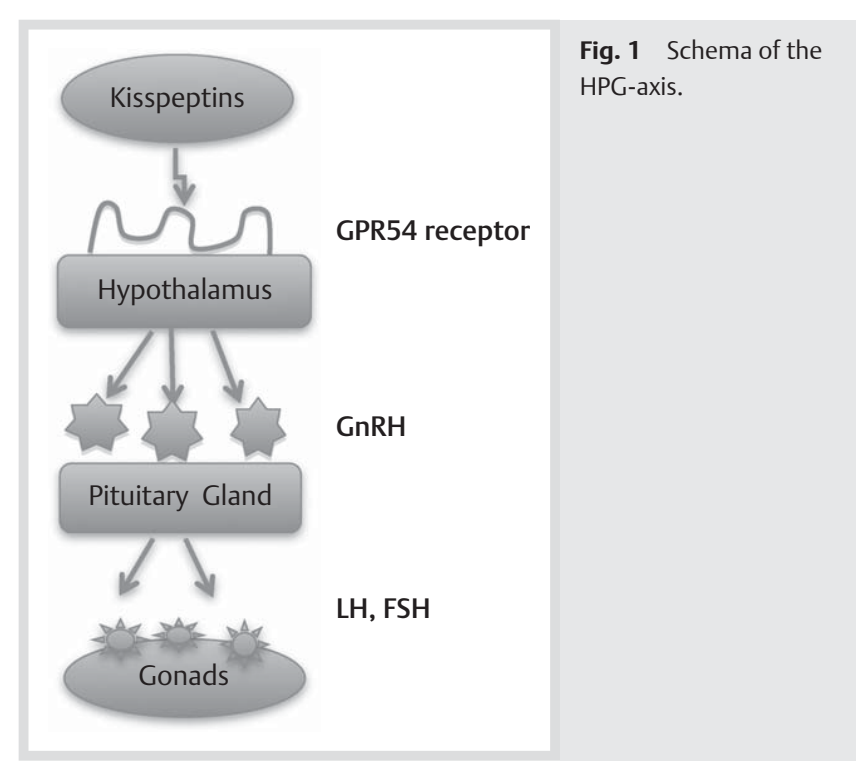

caregiver, after the implant. Furthermore, her mother reported that the worst of her symptoms coincided with the time she was due for a replacement. This behavorial pattern resolved when treatment was no longer necessary and the implant was discontinued.

\section{Discussion \\ $\nabla$}

Puberty is a defining developmental phase both physically and psychosocially, during which a child becomes a young adult. This complex physiologic process results from a "re-awakening": of the hypothalamic-pituitary-gonadal-axis (HPG-axis). GnRH is secreted in a pulsatile fashion, by neurons in hypothalamus, which stimulates the pulsatile release of luteinizing hormone ( $\mathrm{LH})$ and follicle stimulating hormone (FSH) from the anterior lobe of the pituitary gland (Bordini and Rosenfield, 2011). Several mechanisms have been proposed to explain the molecular process that triggers this phenomenon but most reliable theory remains that the hypothalamic G-protein coupled receptor binds to a ligand (kisspeptins) and triggers the pulsatile release of GnRH (Hughes and Kumanan, 2006).

\section{Precocious Puberty}

Studies done by Reynolds and Wines in 1948 revealed that the average age of onset of puberty is 10.8 years. Tanner and Marshall also obtained comparable results in 1969 with an average between 8.5 and 13 years (Muir, 2006; Kandemir et al., 2011) (० Fig. 1).

In the United States, the estimated incidence of precocious puberty (PP) is between $0.01 \%$ and $0.05 \%$ per year and it is 4 to 10 times more common in females as compared to males. It is also more prevalent in African-American females as compared to Caucasian females (Muir, 2006).

The GnRH stimulation test is the gold standard for diagnosing precocious puberty and includes serial measurements of LH and FSH over 90 to $120 \mathrm{~min}$ (Kandemir et al., 2011). Other ancillary studies such as brain MRI, pelvic ultrasound, bone age and thyroid function studies are helpful in supporting the diagnosis and search for an underlying etiology.
Treatment of PP depends on the underlying etiology. Idiopathic central precocious puberty (CPP) accounts for the vast majority of PP and the treatment depends upon the rate of progression, the risk of reduced final adult height as well as the negative psychological impact this may have on the child (Berberoglu, 2009). Gonadotropin releasing hormone agonists (GnRHa) are the mainstay of treatment of CPP and it is effective regardless of the route of administration. The more common treatment modalities include intramuscular leuprolide or triptorelin injections once every 28 days.

Histrelin is a relatively new treatment modality; it is a $30 \mathrm{~mm} \times 3.5 \mathrm{~mm} \times 0.5 \mathrm{~mm}$ sub-dermal rod consisting of a microporus hydrogel that releases about 65ug of histrelin daily (Rachman et al., 1999). The implant is able to effectively suppress the HPG axis for up to 1 year. The advantage of this treatment is that it negates the pain of intramuscular injections every 1 to 3 months so it is less disruptive to the child's life (Berberoglu, 2009; Hirsch et al., 2005).

GnRHa works by desensitizing the pituitary gland through down regulation of $\mathrm{GnRH}$ receptors, which ultimately inhibits the release of LH and FSH. There is usually an initial stimulatory phase characterised by a spike in LH and FSH before complete suppression of these levels (Antoniazzi and Zamboni 2004).

Our patients demonstrated successful suppression of secondary sexual characteristics during their treatments but that success was mitigated by the concurrent psychological side effects.

Transient vaginal withdrawal bleeding can occur in females due to the initial stimulatory phase of the agent (Antoniazzi and Zamboni 2004). An overall decrease in estrogen level can mimic menopausal symptoms such as nausea, depression, insomnia, headaches and hot flashes which, albeit rare, have also been described (Berberoglu, 2009; Antoniazzi and Zamboni 2004). Patients may also develop localized reactions at the injection site, such as induration or sterile abscess.

While other studies have described the use of GnRHa in the treatment of premenstrual symptoms, such as psychosis, hallucinations, emotional lability and unhealthy sexual behaviors, it appears that GnRHa may also be a perpetuator of unwanted psychological effects in susceptible patients.

Several reports have documented psychotic symptoms induced by leuprolide therapy in adult patients. In one case report, the patient had increased irritability, distractibility, pressured speech and hyperactivity after the use of leuprolide for the treatment of endometriosis (Rachman et al., 1999). In a more recent paper, a female who received leuprolide injection as an adjunctive therapy for uterine fibroid experienced racing thoughts, difficult concentrating, became hyper-verbal and developed euphoria (Wahi et al., 2010). Although this medication may have unmasked an underlying psychological illness in these patients, it is also possible that patients with no prior psychiatric history can experience such adverse effects. Furthermore, these potential adverse effects are not limited to female patients. Another recent report is of a male patient with a history of prostate cancer, and no psychiatric history, who became agitated, combative and delusional after leuprolide was begun (Chavez and Reilly, 2010).

Our pediatric patients also had similar experiences; in our first patient, there were no psychological symptoms before therapy was initiated, but she experienced mild symptoms of mood lability while receiving intramuscular leuprolide injections which worsened with the subcutaneous histrelin implant. Our second and third patient had some underlying behavioral 
problems that were further exacerbated by histrelin therapy, with one requiring an inpatient psychiatric intervention. In each case, there was either a complete resolution or a return to baseline in the behavioral pattern once treatments were discontinued. The proposed mechanism is the suppression of estrogen, a hormone that has a mood stabilizing effect in the central nervous system. Estrogen increases the D2-dopamine receptors in the corpus striatum and increases 5HT2a receptors in the frontal lobe, cingulate gyrus, corpus callosum and nucleus acumbens; the areas that control mood and affect (Rachman et al., 1999). Estrogen is also responsible for the modulation of serotonin, a neurotransmitter that plays intricate role in the control of mood, sleep and appetite (Mayeux, 1988; Warnock and Bundren, 1997). Studies in peri-menopausal and menopausal women have shown mood improvement with hormone replacement therapy. Further supporting the fact that estrogen has a mood stabilizing effect on the CNS. Therefore, any factor that inhibits the action of estrogen or decreases its serum levels (such as seen with GnRHa) can potentially trigger mood instability or even psychotic symptoms (Rachman et al., 1999; O'Hara and Schlechte, 1991).

\section{Conclusion}

$\nabla$

To our knowledge, this is the first report describing GnRHainduced behavioral disorders in the pediatric population, and the first report citing not only leuprolide but also histrelin subcutaneous implant. Our experience highlights the potential impact of these therapies on a patient's mental health. More research in this area is needed to better understand the mechanisms by which GnRHa produce these psychological and emotional effects.

\section{Acknowledgements and Conflict of Interests \\ $\nabla$}

The authors would like to thank University of Louisville, department of pediatric endocrinology for their contribution towards this paper. There is no conflict of interest and nothing to declare with regard to financial disclosure.

\section{References}

1 Antoniazzi F, Zamboni G. Central Precocious Puberty: Current treatment. Pediatric Drugs 2004; 6: 211-231

2 Berberoglu M. Precocious Pubert and Normal Variant Puberty: Definition, etiology, diagnosis and current management. Journal of Clinical Research in Pediatric Endocrinology 2009; 1: 164-174

3 Bordini B, Rosenfield RL. Normal pubertal development: part II: clinical aspects of puberty. Pediatrics in Review 2011; 32: 281-292

4 Chavez B, Reilly T. Manic and psychotic symptoms following subcutaneous leuprolide in a male patient with no prior psychiatric history. Journal of Clinical Psychiatry 2010; 71: 1696-1698

5 Hirsch HJ, Strich D, Chertin B, Farkas A, Lindenberg T, Gelber H, Spitz IM. The Histrelin Implant: A Novel Treatment in Central Precocious Puberty. Pediatrics 2005; 116: 798

6 Hughes IA, Kumanan M. A wider perspective on puberty. Mol Cell Endocrinol 2006; 254-255: 1-7

7 Kandemir N, Demirbilek H, Ozon ZA, Gonc N, Alikasifoglu A. GnRH stimulation test in precocious puberty: single sample is adequate for diagnosis and dose adjustment. J Clin Res Pediatr Endocrinol 2011; 3: $12-17$

8 Mayeux $R$. The relationship of serotonin to depression in Parkinson's disease. Movement Disorders 1988; 3: 237-244

9 Muir A. Precocious Puberty. Pediatrics in Review 2006; 27: 373-381

10 Rachman M, Garfield DdA, Rachman I, Cohen R. Lupron-induced mania. Biological Psychiatry 1999; 45: 243-244

11 O'Hara MW, Schlechte JA. A Prospective study of postpartum blues. Biologic and psychosocial factors. Archives of General Psychiatry 1991; 48: 801-806

12 Wahi MM, Skeate RC, Goldin SB, Santana CA. A second case report of Leuprolide acetate for depot suspension-induced mania. Cambridge University Press, 2010; 15: 603-606

13 Warnock JK, Bundren JC. Anxiety and mood disorders associated with gonadotropin-releasing hormone agonist therapy. Psychopharmacology Bulletin 1997; 33: 311-316 